\title{
1 Perforation Resistance of CFRP Beams to Quasi-static and Ballistic \\ Loading: The Role of Matrix Strength
}

\author{
${ }^{b}$ School of Engineering, De Montfort University, The Gateway, Leicester LE1 9BH, UK \\ B. Yu ${ }^{a}$, K. Karthikeyan ${ }^{b}$, V.S. Deshpande ${ }^{a}$, N.A. Fleck ${ }^{a 1}$ \\ ${ }^{a}$ Department of Engineering, University of Cambridge, Trumpington St., Cambridge, CB2 1PZ, UK
}

6 Abstract

The effect of matrix shear strength on the ballistic response of simply-supported carbon fibre reinforced plastic (CFRP) beams was explored for a flat-ended projectile. To gain insight into the deformation and failure mechanisms, the following additional tests were performed on CFRP beams: (i) quasi-static indentation tests with rigid back support and, (ii) quasi-static cropping tests. In all 3 types of tests, CFRP $\left[0^{\circ} / 90^{\circ}\right]$ cross-ply laminates were tested in six states of cure, such that the matrix shear strength ranges from $0.1 \mathrm{MPa}$ to $100 \mathrm{MPa}$. In the quasi-static cropping tests, the composite beams failed by shear plugging (involving transverse matrix cracks, ply delamination, and fibre fracture). In contrast, indirect tension (by ply tensile failure in the fibre direction) occurred in the back-supported quasi-static indentation tests. In the ballistic tests, the CFRP beams of high matrix shear strength (30 MPa to $100 \mathrm{MPa}$ ) failed by a shear plugging mode. When the matrix shear strength was less than $30 \mathrm{MPa}$, the failure mode and the penetration velocity doubled and occurred by indirect tension. The optimal shear strength to give adequate static and ballistic strength is on the order of $20 \mathrm{MPa}$.

Keywords: ballistics, fibre composites, perforation mechanisms, shear plugging, indirect tension

\footnotetext{
${ }^{1}$ Corresponding author. Tel.: +44-1223-748240; fax: +44-1223-332662. E-mail address: naf1@eng.cam.ac.uk
} 
Carbon fibre reinforced plastic (CFRP) composites offer high stiffness and strength but have a ballistic performance that is inferior to that of ultrahigh molecular weight polyethylene Dyneema ${ }^{\circledR}$ cross-ply laminates. This study explores whether the ballistic resistance of CFRP composites can be improved by altering the matrix shear strength, as motivated by the observation that Dyneema ${ }^{\circledR}$ possess a low shear strength.

Recent investigations have suggested that the high impact resistance of Dyneema ${ }^{\circledR}$ cross-ply composites is by the failure mechanism of indirect tension [1]-[5]. This indirect tension mechanism has also been observed in Dyneema ${ }^{\circledR}$ cross-ply composites under quasistatic out-of-plane uniaxial compression, see Attwood et al. [2]. The indirect tension mechanism is best understood by considering a stack of alternating $0^{\circ}$ and $90^{\circ}$ plies under out-of-plane compression in the $z$-direction, as shown in Fig. 1. Limit attention to the response of a unit cell comprising a single $0^{\circ}$ ply (labelled $\mathrm{A}$ in the figure) adhered to an underlying $90^{\circ}$ ply (labelled B). If the faces of the two plies were allowed to slip freely, then an out-ofplane compressive load will cause ply B to undergo a much larger Poisson expansion in the $y$ direction than ply A, due to the orientation-dependent Poisson ratio. Adhesion between the two layers implies that they share the same direct strain component in the $y$-direction; consequently, layer A is subjected to a tensile stress $\sigma_{y y}^{A}$, whereas layer B experiences a compressive stress $\sigma_{y y}^{B}=-\sigma_{y y}^{A}$ with no net traction on the section with unit normal in the $y$-direction. By symmetry, $\sigma_{x x}^{B}=\sigma_{y y}^{A}$ and $\sigma_{x x}^{A}=\sigma_{y y}^{B}$. We conclude that out-of-plane compression generates axial tension in the fibre direction for each ply: hence the description 'indirect tension'.

O'Masta et al. [4] observed that indirect tension is the active failure mechanism for Dyneema ${ }^{\circledR}$ cross-ply laminates due to impact by a projectile. In contrast, ballistic loading of a cross-ply CFRP composite induces shear plugging, as reported by Cantwell and Morton [6][8] for drop weight tests on CFRP layers. This mechanism has also been observed in quasistatic punch tests and in ballistic tests on carbon fibre and glass fibre composites [9]-[17]. The difference in dynamic failure mechanism for CFRP and Dyneema ${ }^{\circledR}$ may be due to the large difference in matrix shear strength. Whereas Dyneema ${ }^{\circledR}$ composites possess a shear strength on the order of 1 - $10 \mathrm{MPa}$, commercially available CFRP composites with fully cured epoxy 
matrix possess a shear strength in the range $50-100 \mathrm{MPa}$ [18]-[22]. In support of the role played by the matrix shear strength on ballistic performance, Karthikeyan et al. [1] demonstrated that uncured CFRP laminate has a higher ballistic limit than that of the fully cured CFRP laminate. A strong dependence of ballistic limit on matrix properties is also deduced from the tests of de Ruijter et al. [23] on an aramid-based composite, although the penetration mechanism was not determined.

The objective of the current study is to provide a comprehensive experimental investigation to understand: (i) the effect of matrix cure on the failure mechanism and ballistic resistance of CFRP composites, (ii) the difference in quasi-static and dynamic response of CFRP composites, and (iii) the potential to improve the ballistic resistance of CFRP composites by suppressing the shear plugging mechanism. To achieve this objective, composite beams were manufactured with various states of cure and then subjected to three types of tests: (i) a quasi-static indentation test with rigid back support, (ii) a quasi-static cropping test, and a (iii) ballistic impact test using a flat-ended projectile.

\section{Specimen Manufacture}

Cross-ply laminates $\left[0^{\circ} / 90^{\circ}\right]_{16}$ were assembled from Hexply ${ }^{\circledR}$ 8552/35\%134/IM7 carbon fibre/epoxy prepregs (with a ply thickness of $0.131 \mathrm{~mm}$ ). Six states of cure were considered, with the following labelling procedure employed throughout this study: (A) uncured, (B) partially cured at $100^{\circ} \mathrm{C}$ for 2 hours, (C) partially cured at $120^{\circ} \mathrm{C}$ for 2 hours, (D) partially cured at $120^{\circ} \mathrm{C}$ for 2 hours and 15 minutes, (E) partially cured at $180^{\circ} \mathrm{C}$ for 24 hours, and (F) autoclaved fully cured specimens.

The laminates were laid-up by hand, and then cut using a band saw into rectangular beams dimensions of height $H=4 \mathrm{~mm}$ (32 plies), breadth $B=11 \mathrm{~mm}$, length $L=300 \mathrm{~mm}$, and areal density $\rho_{A}=6.28 \mathrm{~kg} / \mathrm{m}^{2}$. A portion of these uncured beams were tested in this state (A). The partially cured composites of types (B) to (E) were prepared by placing most of the uncured beams in an air-oven using the above-mentioned cure cycles and were compressed insitu at $0.1 \mathrm{MPa}$ in the out-of-plane direction by spring-loaded platens. The fully cured specimens (F) were autoclaved following the procedure recommended by Hexcel Ltd. [24]. The matrix shear strength of the laminates was then measured by performing short beam shear test at a quasi-static loading rate (following the recommendation in ASTM standard D2344). 
The shear tests are given in Appendix A. Table 1 summarises the curing process and the matrix shear strength and the shear modulua of laminates type (A) to (F). With the exception of the fully cured material (F), all laminates were stored at $-15^{\circ} \mathrm{C}$ to avoid further curing and slowly re-elevated to room temperature over a period of 5 hours prior to testing. With the exception of the fully cured material $(\mathrm{F})$, all laminates were stored at $-15^{\circ} \mathrm{C}$ for a duration of less than 30 days (a duration well below the expiry date of the prepregs) to avoid further curing and slowly re-elevated to room temperature over a period of 5 hours prior to testing.

\section{$3 \quad$ Test Methods}

\subsection{Quasi-Static Indentation Tests}

CFRP composite beams with rectangular dimensions of height $H=4 \mathrm{~mm}$ (32 plies), breadth $B=11 \mathrm{~mm}$, and the reduced length $L=75 \mathrm{~mm}$ were sectioned from the cross-ply laminates $\left[0^{\circ} / 90^{\circ}\right]_{16}$ (32 plies) in six states of cure, as described in the previous section. Specimens were subjected to an out-of-plane indentation test by placing them between a flat back support and a hardened steel indenter with a square bottom of plan dimension $l_{1}=l_{2}=12.5 \mathrm{~mm}$ in the $x-y$ plane, as illustrated in Fig. 2a. A small edge radius $R=0.3 \mathrm{~mm}$ was introduced to reduce the stress concentration of the indenter. Both the back support and the indenter were made from hardened silver steel (700 Vickers) and were lubricated with a low viscosity mineral oil in order to reduce the role of friction.

Materials (A) and (B) were tested using a screw-driven test machine with a $150 \mathrm{kN}$ load cell, whereas materials (D) to (F) were tested using a servo hydraulic test machine with a $1 \mathrm{MN}$ load cell. For consistency, all specimens were tested with the fibres of the top ply lying parallel to the $x$-direction in the figure. The indenter was then displaced along the $z$-direction such that it contacted the central point of the top face of the specimens. Indentation tests were performed at a constant displacement rate of $\dot{u}_{z}=4 \times 10^{-3} \mathrm{~mm} / \mathrm{s}$. The indentation load $F$ was recorded by the machine load cell and the displacement between the steel plate and the indenter $u_{z}$ was measured using a laser extensometer. During the indentation test, high-speed images were recorded from the side-view of the specimens using a Phantom ${ }^{\circledR} \mathrm{V} 1610^{1}$ camera with an interframe time of $100 \mu \mathrm{s}$ and an exposure time of $90 \mu \mathrm{s}$ in order to identify the failure mechanism.

\footnotetext{
${ }^{1}$ Vision Research Inc., 100 Dey Road, Wayne, New Jersey 07470, USA.
} 


\subsection{Quasi-Static Cropping Tests}

113 CFRP composite beams with same rectangular dimensions as for the indentation test

114 were subjected to a cropping test at a quasi-static loading rate using a screw-driven test machine

115 with a $150 \mathrm{kN}$ load cell. Specimens were placed between a hardened steel indenter (with a 116 square bottom of $l_{1}=l_{2}=12.5 \mathrm{~mm}$ in the $x-y$ plane) and two back supports of spacing 18.5

$117 \mathrm{~mm}$, thereby creating a clearance $c=3 \mathrm{~mm}$ (with $c / H=0.75$ ) between the steel supports 118 and the indenter (see Fig. 2b). Again, a radius $R=0.3 \mathrm{~mm}$ was introduced into the edges of 119 the indenter and the steel support in order to reduce the stress concentration. Both the supports 120 and the indenter were made from hardened silver steel (700 Vickers) and were lubricated with 121 a low viscosity mineral oil. As for the indentation tests, the specimens were placed so that the 122 fibres in the top ply were parallel to the $x$-direction in the figure. The average shear strain in 123 the specimen $\bar{\gamma}$ exists within the clearance $c$ between indenter and back support; this shear strain scales with the indenter displacement $u_{z}$ according to $\bar{\gamma}=u_{z} / c$.

The cropping test was performed at an out-of-plane displacement rate of $\dot{u}_{z}=3 \times 10^{-3} \mathrm{mms}^{-1}$ (to generate an average shear strain rate of $10^{-3} s^{-1}$ ). The compressive load $F$ was recorded by the machine load cell and the displacement $u_{z}$ between the steel plate and the indenter was measured using a laser extensometer. Side-view optical images of the specimen were recorded during the cropping test using a digital camera with a resolution of $2048 \times 1536$ (3.1 megapixel), and a flame rate of 12 FPS at full resolution. For maximum resolution, only a 9 $99 \mathrm{~mm}$ window of one side of the punched regions was filmed. The preliminary tests revealed that a peak load accompanies damage initiation at a shear strain of $\bar{\gamma}=10 \%$. Additional interrupted tests were performed on specimens at each state of cure: the specimens were loaded to shear strain levels of $\bar{\gamma}=10 \%$ and $\bar{\gamma}=40 \%$, followed by unloading and optical examination.

\subsection{Ballistic Tests}

CFRP composite beams with rectangular dimensions of height $H=4 \mathrm{~mm}$ (32 plies), breadth $B=11 \mathrm{~mm}$, and length $L=300 \mathrm{~mm}$ were subjected to ballistic impact by a cuboid

140 shaped projectile under a simply supported boundary condition. The beam configuration

141 allowed direct observation of the damaged areas and the cuboid shape assisted in identifying 142 the location of the damage in relation to point of contact. 
144 adhesive tape so that they had a span length $L_{S}=250 \mathrm{~mm}$ (as illustrated in Fig. 2c). Specimens

145 were placed with the fibres of the top ply lying parallel to the $x$-direction in the figure. The 146 centre of the top face of the specimens was impacted in the out-of-plane direction using a

147 hardened steel cuboid shaped projectile with a square cross-section of $l_{1}=l_{2}=12.5 \mathrm{~mm}$ in

148 the $x$-y plane, a length $l_{3}=9 \mathrm{~mm}$ in the $z$-direction, and a mass of $m_{p}=1.1 \times 10^{-2} \mathrm{~kg}$. As

149 before, a radius $R=0.3 \mathrm{~mm}$ was introduced into the projectile edges to reduce the stress

150 concentration. Projectiles were launched using a gas gun (utilising helium or nitrogen

151 compressed gas) with an aluminium alloy barrel $4.5 \mathrm{~m}$ in length and with an inner cross-section

152 of $13 \times 13 \mathrm{~mm}$ (the same apparatus was described by [5]). The gas gun was capable of producing 153 impact velocities of $v_{0}=25 \mathrm{~ms}^{-1}$ to $v_{0}=550 \mathrm{~ms}^{-1}$. The impact velocity $v_{0}$ was measured using 154 a set of laser gates placed near the gun barrel's exit. During the ballistic test, high-speed images

155 were recorded from the side-view of the specimens using a Phantom ${ }^{\circledR}$ V1610 camera ${ }^{1}$ with an 156 inter-frame time of $7.7 \mu \mathrm{s}$ and an exposure time of $0.43 \mu \mathrm{s}$. The as-tested specimens were 157 examined using an optical microscope to determine the level of damage (i.e. number of failed 158 plies) and to identify the failure mechanisms.

\section{$159 \quad 4 \quad$ Results}

\section{$160 \quad$ 4.1 Quasi-static Indentation Tests}

161 The quasi-static indentation tests on CFRP composite beams of type (A) to (F) gave 162 rise to catastrophic failure accompanied by acoustic emission. The indentation responses are 163 plotted in Fig. 3 in terms of the average indentation pressure under the indenter $\bar{p}$ and the 164 average out-of-plane compressive strain $\bar{\varepsilon}$ in the material directly beneath the projectile, where

$$
\bar{p}=\frac{F}{B l_{1}}
$$

166 and

$$
\bar{\varepsilon}=\frac{u_{z}}{H}
$$

\footnotetext{
${ }^{1}$ Vision Research Inc., 100 Dey Road, Wayne, New Jersey 07470, USA.
} 
168 All specimens showed catastrophic failure at a critical average pressure of $\bar{p}_{c}$ at

$169 \bar{\varepsilon}=15-20 \%$. The magnitude of $\bar{p}_{c}$ was comparable to that of the average failure pressure

$170 \bar{p}_{f}$ from uniaxial compression tests in the out-of-plane direction, as observed in a companion

171 study [25]. An explicit comparison of $\bar{p}_{c}$ and $\bar{p}_{f}$ is given in Table 2; the peak pressures are

172 all on the order of $1 \mathrm{GPa}$. We note in passing that the indirect tension mechanism was

173 responsible for failure in these uniaxial compression tests.

174 The value of $\bar{p}_{c}$ increased with the state of matrix cure in the indentation tests, and 175 ranged from $\bar{p}_{c}=761 \mathrm{MPa}$ for the uncured laminate (A) to $\bar{p}_{c}=1250 \mathrm{MPa}$ for material (F).

176 High speed photography was used to reveal the failure mechanism, as follows. Fig. 4 shows

177 high-speed image sequences during the indentation test for the moments before and after the

178 onset of failure (where $t=0$ corresponding to the instant of failure). The results for materials

179 (A) and (F) were selected to be shown here, as these represent the two extremes of matrix shear

180 strength. The images demonstrate that the materials failed catastrophically, with ply tensile

181 failure occurring directly beneath the indenter. Furthermore, the similarity of this indentation

182 pressure measurement to that obtained from the out-of-plane compression test supports the

183 conclusion that the composite beams failed by an indirect tension mechanism in the indentation 184 tests.

185

186

187

188

\subsection{Quasi-Static Cropping Tests}

Define the average shear stress within the clearance $\mathrm{c}$ between the edge support and a flat punch by

$$
\bar{\tau}=\frac{F}{2 B H}
$$

and

$$
\bar{\gamma}=\frac{u_{z}}{c}
$$

respectively. Then, the $\bar{\tau}$ versus $\bar{\gamma}$ response is summarised in Fig. 5 for samples (A) to (F) of the quasi-static cropping tests. Two types of response were observed. Materials (A) and (B) showed a ductile shear response without failure; the shear stress increased continuously throughout the test. In contrast, materials $(\mathrm{C})$ to $(\mathrm{F})$ exhibited an initial peak stress $\bar{\tau}_{c}$ at 
$195 \bar{\gamma} \sim 10 \%$ followed by a load drop and a subsequent hardening response up to $\bar{\gamma} \sim 20 \%$; a

196 sequence of load drops ensued at $\bar{\gamma} \sim 30-40 \%$.

Additional interrupted tests were performed on the selected materials (A), (C), and (F)

198 by loading the specimens up to $\bar{\gamma}=10 \%$ and $40 \%$, followed by unloading, in order to gain insight into the progression of failure. During the interrupted tests, optical images of the specimens were recorded, see Fig. 6. For material (A), plastic shear was observed in the clearance zone between edge support and the indenter at $\bar{\gamma}=10 \%$; delaminations were also observed at $\bar{\gamma}=40 \%$. For materials (C) and (F), fibre fracture in the top ply and transverse ply failure in lower plies initiated beneath the corner of the indenter at $\bar{\gamma}=10 \%$, and shear cracks developed across the thickness of the specimen at $\bar{\gamma}=40 \%$, see Fig. $6 \mathrm{~d}$.

The measured shear strength from the cropping test $\bar{\tau}_{c}$ is compared in Table 3 with the matrix shear strength of the laminates as measured from the short beam shear test $\tau$. The average shear strengths in the cropping test $\bar{\tau}_{c}$ are comparable to those obtained in the short beam shear test (we note that the lower values of $\bar{\tau}_{c}$ is attributed to the stress concentration associated with the corners of the indenter).

\subsection{Ballistic Tests}

Ballistic tests were performed on the composite beams at impact velocities $v_{0}$ ranging

213 from $45 \mathrm{~ms}^{-1}$ to $355 \mathrm{~ms}^{-1}$. For any given impact velocity, define the ratio $f$ as the number of plies that show fibre failure divided by the total number of plies in the specimen (32 plies).

215 Then, the fraction of cut plies $f$ is plotted as a function of projectile velocity $v_{0}$ in Fig. 7. Two critical velocities can be defined: $v_{\text {init }}$ is the velocity at initiation of failure (i.e. $f=0^{+}$), and $v_{p}$ is the penetration velocity (i.e. $f=1$ ). $v_{\text {init }}$ is identified as the average of the lowest

218 velocity resulting in damage to the target and the highest velocity that did not lead to damage of the target. In similar fashion, $v_{p}$ is identified as the average of the lowest velocity resulting in full penetration of the target and the highest velocity resulting in partial penetration of the target. Values for $v_{\text {init }}$ for materials $(\mathrm{A}),(\mathrm{C})$, and $(\mathrm{F})$ and for $v_{p}$ in materials $(\mathrm{A})$ to $(\mathrm{F})$ are summarised in Table 4. 
In general, both $v_{\text {init }}$ and $v_{p}$ decrease as the state of matrix cure increases from material (A) to (F). The effect of matrix shear strength on ballistic resistance is apparent in Fig. 8 , where $v_{\text {init }}$ and $v_{p}$ are plotted against the matrix shear strength $\tau$ in semi-log scale. There exist two regimes of ballistic behaviour, with a transition point at $\tau=22 \mathrm{MPa}$ that corresponds to material (C). In the regime where $\tau$ exceeds $22 \mathrm{MPa}$, specimens show lower ballistic resistance. For instance, the fully cured material $(\mathrm{F})$ shows the lowest ballistic resistance: $v_{\text {init }}=64 \mathrm{~ms}^{-1}$ and $v_{p}=148 \mathrm{~ms}^{-1}$. The magnitude of both $v_{\text {init }}$ and $v_{p}$ increase as the matrix shear strength decreases to the value $\tau=22 \mathrm{MPa}$ and thereafter remain constant. For example, the uncured material (A) shows a significantly higher ballistic resistance with $v_{\text {init }}=141 \mathrm{~ms}^{-1}$ and $v_{p}=323 \mathrm{~ms}^{-1}$. This sudden change in the relationship between $\tau$ and $v_{p}$ indicates a switch in failure mode at $22 \mathrm{MPa}$.

Figure 9 contains post-test evidence that materials (A) and (C) failed by indirect tension whereas materials (D) and (F) failed by shear plugging. The top views of materials (A) and (C) reveal that fibre tensile failure occurred at multiple locations beneath the projectile, see Fig. 9a. Furthermore, the profile view of material (A) shows that the $90^{\circ}$ plies are extruded out from the edge of the specimen beneath the projectile. This is consistent with the mechanism of indirect tension. For materials (D) to (F), fibre failure was not observed beneath the projectile. Instead, failure of these specimens was caused by transverse matrix cracks, ply delamination, and fibre fracture beneath the edge of contact, see Fig. 9b. This mechanism is commonly observed in carbon/epoxy composites and is referred to as shear plugging.

Fig. 10 shows a sequence of high-speed images in profile view of the composite beams impacted at velocities just above their failure initiation velocity $v_{\text {init }}: v_{0}=158 \mathrm{~ms}^{-1}$ for materials (A) and (C), and $v_{0}=73 \mathrm{~ms}^{-1}$ for material (F). Materials (A) and (C) failed by an indirect tension mechanism that is facilitated by ply tensile failure. In contrast, material (F) failed by the shear plugging mode. Furthermore, the high-speed images revealed the time at which fibre failure was first observed $t_{f}$ (referred to here as failure time): $t_{f}=10.4 \mu \mathrm{s}$ in material $(\mathrm{A}), t_{f}=11.6 \mu \mathrm{s}$ in material $(\mathrm{C})$, and $t_{f}=53.8 \mu \mathrm{s}$ in material $(\mathrm{F})$. 


\subsection{Failure Mechanisms in the Quasi-static Indentation and Cropping Tests}

In the current study, shear plugging and indirect tension are the two observed and competing mechanisms in the composite cross-ply beams. When a composite beam is supported on a rigid foundation as in the indentation test, out-of-plane shear deformation of the composite beam is prohibited and the shear plugging mechanism is suppressed. Consequently, the specimens failed by indirect tension at an average indentation pressure $\bar{p}_{c}$ ranging from $761 \mathrm{MPa}$ to $1250 \mathrm{MPa}$ (as summarised in Table 2). Attwood et al. [5] have conducted a similar back-supported indentation test with a flat indenter on Dyneema ${ }^{\circledR}$ cross-ply beams. Their results are in agreement with the overall failure mechanism observed in the current study. Conversely, when a composite beam is subjected to a cropping test, shear plugging becomes a possibility (as sketched in Fig. 11b), and is activated if the shear plugging force is less than that for indirect tension. This is now made precise.

$$
F_{S P}=2 \tau H B
$$

However, if the contact pressure underneath the indenter reaches the out-of-plane compressive strength of the material, the laminate fails by indirect tension. In the cropping test, the load required to cause indirect tension failure $F_{I T}$ can be estimated by:

$$
F_{I T}=\bar{p}_{c} l_{1} B
$$

The failure mechanism is determined by the ratio $F_{S P} / F_{I T}$ :

$$
\frac{F_{S P}}{F_{I T}}=\frac{2 \tau H}{\bar{p}_{c} l_{1}}
$$

271 The shear plugging mechanism occurs when $F_{S P} / F_{I T}<1$ and the indirect tension mechanism

272 occurs when $F_{S P} / F_{I T}>1$. Thus, failure mechanism is sensitive to the material properties

273 (i.e. $\tau / \bar{p}_{c}$ ) and the specimen geometry (i.e. $2 H / l_{1}$ ). In the current study, $l_{1}=12.5 \mathrm{~mm}$, $274 H=4 \mathrm{~mm}, \tau$ ranges from $0.11 \mathrm{MPa}$ in material (A) to $99 \mathrm{MPa}$ in material $(\mathrm{F})$, and $\bar{p}_{c}$ ranges 275 from $761 \mathrm{MPa}$ in material (A) to $1250 \mathrm{MPa}$ in material $(\mathrm{F})$. Thus, the calculated ratio 
$276 F_{S P} / F_{I T}$ ranges from $10^{-4}$ in material (A) to 0.06 in material $(\mathrm{F})$. Both values are much 277 below unity, which explains the current study's findings that all specimens failed by shear 278 plugging in the cropping test. However, if $2 \mathrm{H} / l_{1}$ were to increase from the current value of 2790.73 to 20 , the ratio $F_{S P} / F_{I T}$ would then increase to range from $3 \times 10^{-3}$ in material (A) to 2801.6 in material $(F)$. This suggests that the failure mechanism can potentially change from shear 281 plugging to indirect tension when the state of matrix cure increases from material (A) to 282 material $(\mathrm{F})$.

\subsection{Failure Mechanisms in the Ballistic Tests}

Materials (D) to (F) have a high matrix shear strength (30 to $100 \mathrm{MPa}$ ) and fail by a brittle shear plugging mode in the ballistic tests. As the matrix shear strength is reduced from $100 \mathrm{MPa}$ to $22 \mathrm{MPa}$, both the initiation velocity $v_{\text {init }}$ and the penetration velocity $v_{p}$ double. When the matrix shear strength is below $22 \mathrm{MPa}$, indirect tension is activated, see the results for materials (A) to (C). In this failure regime, the penetration velocity remains elevated and is independent of the matrix shear strength. The underlying reason for the change in failure mechanism remains unclear. Also, the sensitivity of ballistic resistance to matrix shear strength differs from the sensitivity of cropping force to shear strength: whereas the penetration velocity increases as matrix shear strength decreases, the opposite trend is observed in the quasi-static cropping test (i.e. the indentation load required to cause shear plug formation scales with the matrix shear strength).

A similar sensitivity of ballistic resistance to the choice of matrix has been observed by de Ruijter et al. in ballistic tests on aramid composites with different grades of semi-flexible thermotropic liquid crystalline polyesters and poly(ester-amide)s matrices [23]. They observed that the penetration velocity of these aramid laminates was independent of the matrix modulus within the range of $0.01 \mathrm{GPa}$ to $1 \mathrm{GPa}$, whereas the penetration velocity decreased along with the matrix modulus in the range of $1 \mathrm{GPa}$ to $10 \mathrm{GPa}$. They proposed that, at the high modulus level (i.e. $1 \mathrm{GPa}$ to $10 \mathrm{GPa}$ ), the increase in friction between the fibres may result in a reduction in fibre mobility and give rise to premature fibre breakage. Their results are in agreement with the findings of the current study, although their interpretation differs. 


\subsection{Estimation of Penetration Velocity}

The penetration velocity of composite beams can be estimated as follows. In the case of indirect tension, as observed in materials (A) to (C), failure occurs if the contact pressure beneath the projectile reaches the out-of-plane compressive strength of the material. The energy required to cause indirect tension failure $E_{I T}$ can be estimated as:

$$
E_{I T}=\int_{0}^{H} \bar{p}_{c} l_{1} B d H=\bar{p}_{c} l_{1} B H
$$

where $\bar{p}_{c}$ is the failure pressure measured from the quasi-static indentation test. The penetration velocity of the indirect tensile failure mechanism $v_{I T}$ can be estimated by equating $E_{I T}$ with the kinetic energy of the projectile:

$$
v_{I T}=\sqrt{\frac{2 \bar{p}_{c} l_{1} B H}{m_{p}}}
$$

where $m_{p}$ is the mass of the projectile $\left(1.1 \times 10^{-2} \mathrm{~kg}\right)$.

In the case of shear plugging, as observed in materials (D) to (F), failure can occur if the shear stress underneath edge of contact reaches the shear strength of the laminate. The energy required to cause shear plugging $E_{S P}$ can be estimated as:

$$
E_{S P}=\int_{0}^{H} 2 \bar{\tau}_{c} B H d H=\bar{\tau}_{c} B H^{2}
$$

where $\bar{\tau}_{c}$ is the shear strength measured from the quasi-static cropping test. The penetration velocity that causes shear plugging $v_{S P}$ can be estimated by equating $E_{S P}$ with the kinetic energy of the projectile:

$$
v_{S P}=\sqrt{\frac{2 \bar{\tau}_{c} B H^{2}}{m_{p}}}
$$

324 The predicted value of $v_{I T}$ in Eq. (9) is compared with the measured penetration velocity $v_{p}$ in Fig. 12a for materials (A) to (C), as a function of $\bar{p}_{c}$. This simple model underpredicts $v_{p}$ 

can also be made. They performed ballistic tests on rectangular beams made from Dyneema ${ }^{\circledR}$ cross-ply laminates using a flat-ended projectile and measured the dependence of $v_{p}$ upon projectile mass $m_{p}$. We found that $v_{I T}$ in Eq. (9) overpredicts $v_{p}$ for the Dyneema ${ }^{\circledR}$ crossply beams by $0-40 \%$ depending upon the magnitude of $m_{p}$.

Likewise, the predicted value of $v_{S P}$ in Eq. (11) is compared with the measured penetration velocity $v_{p}$ of materials (D) to (F) in Fig. $12 \mathrm{~b}$, as a function of $\bar{\tau}_{c}$. We find that the predicted $v_{S P}$ significantly underestimates the penetration velocity $v_{p}$. Part of this discrepancy could be attributed to the strain rate effect of the matrix shear strength. Hopkinson bar experiments on CFRP composites from the available literature have shown that matrix shear strength has a strain rate dependency and typically rises $50 \%$ to $100 \%$ as the strain rate increases from $10^{-3} s^{-1}$ to $10^{3} s^{-1}$ [26]-[31]. However, this rate dependency is insufficient to account for the discrepancy between the predicted value $v_{S P}$ and measured value $v_{p}$ for materials (D) to (F).

339 Furthermore, the above prediction of $v_{S P}$ suggests that the penetration velocity is proportional 340 to the magnitude of $\bar{\tau}_{c}$. An opposite trend was observed for the measured value of $v_{p}$ for materials $(\mathrm{D})$ to $(\mathrm{F})$.

\subsection{The Effect of Perforation Mechanism on the Failure Time}

The above analysis demonstrated that the indirect tension failure observed in materials

344 (A) to (C) is generated by the contact pressure $p$ between the projectile and the composite laminate. O'Masta et al. [4] recently observed that Dyneema ${ }^{\circledR}$ cross-ply laminates also fail by the same indirect tension mechanism in an edge-clamped ballistic experiment [4]. They proposed that the indirect tension mechanism of Dyneema ${ }^{\circledR}$ cross-ply laminates can be generated by the compressive pressure pulse due to impact. They stated that, at the onset of impact, a compressive stress wave travels through the thickness of the laminate from the projectile to the distal face at a speed of approximately $c_{T} \sim \sqrt{E_{T} / \rho}$, where $E_{T}$ is the throughthickness tangent modulus and $\rho$ is the density, with a peak pressure $p$ scaling as $\rho c_{T} v_{0}$. When the wave front reaches the free boundary at the back face (at $t=H / c_{T}$ where $H$ is the thickness of the laminate), the stress wave reflects back as a tensile wave towards the projectile. 
354 The contact pressure at the top face is partially relieved when this wave arrives to the top (at $\left.t=2 H / c_{T}\right)$.

Recall that the high-speed images of the current study revealed that laminates failing by indirect tension, such as materials $(\mathrm{A})$ and $(\mathrm{C})$, have lower failure times $t_{f}(\sim 10 \mu \mathrm{s})$ than material $(\mathrm{F})(\sim 54 \mu \mathrm{s})$, which failed by shear plugging, see Fig. 13. Define $t_{f}$ as the postimpact time when fibre failure is first observed for an impact velocity just above $v_{\text {init }}$. Fig. 13 presents these data by plotting a dimensionless parameter $n=t_{f} c_{T} / H$ as a function of the matrix shear strength $\tau$ of the laminates. $n$ represents the number of transverse wave

reflections before first failure occurs. In the figure, the transverse wave speeds $c_{T}^{(i)}$ and $c_{T}^{(i i)}$ were calculated based on the through-thickness tangent modulus of the composite beams measured from the quasi-static indentation tests at $\bar{\varepsilon}=5 \%$ and $10 \%$, respectively (see Table 2). Fig. 13 shows that laminates which fail by indirect tension, such as materials (A) and (C), have low failure times $t_{f}$ and the number of wave reflections before failure $n$ can be as low as 2 to 5 , in agreement with the premise given by O'Masta et al. [4]. In contrast, material (F), which fails by shear plugging, has a high failure time $t_{f}$ and the number of wave reflections before failure $n$ can be as high as 25 to 30 .

\section{Conclusions}

The penetration resistance and failure mechanisms of $\left[0^{\circ} / 90^{\circ}\right]_{16}$ CFRP composite beams in six different states of matrix cure were measured in 3 types of test: (i) a quasi-static indentation test with rigid back support, (ii) a quasi-static cropping test with a finite clearance between edge support and a flat indenter, and (iii) a ballistic impact test using a cuboid shaped projectile under a simply supported boundary condition.

The composite beams that were subjected to quasi-static indentation with rigid back supports all exhibited an indirect tension failure mode that consisted of ply-by-ply tensile failure in the local fibre direction. Composite beams that were subjected to quasi-static cropping tests failed in a shear plugging mode that involved transverse matrix cracks, ply delamination, and fibre fracture beneath the edge of contact. In the ballistic impact tests, CFRP beams with a high matrix shear strength (30 to $100 \mathrm{MPa}$ ) failed by a brittle shear plugging mode. As the matrix shear strength was reduced from $100 \mathrm{MPa}$ to $22 \mathrm{MPa}$, the penetration 
383 velocity doubled. Once the matrix shear strength had decreased below $22 \mathrm{MPa}$, the failure 384 mode switched to indirect tension. In this failure regime, the penetration velocity remained 385 elevated and was independent of matrix shear strength. Specimens with matrix shear strength 386 of $22 \mathrm{MPa}$ appear to offer both acceptable penetration resistance and structural performance.

387 The above findings suggest a research direction for increasing the ballistic resistance of 388 CFRP laminates. At present, CFRP laminates offers superior structural properties under quasi389 static loading conditions but provides weaker impact resistance in dynamic environments

390 compared to composites manufactured from flexible fibres such as Dyneema ${ }^{\circledR}$ and $\operatorname{Kevlar}^{\circledR}$.

391 We attribute this reduced ballistic resistance to a brittle shear plugging failure mode and we 392 demonstrate that the impact resistance can be increased by the reduction of matrix shear 393 strength. This creates the possibility of designing composite structural armour from CFRP 394 laminates that can offer high impact resistance joined with adequate structural performance.

\section{Acknowledgements}

396 The research work was sponsored by the Office of Naval Research (ONR), U.S. (Prime Award 397 No. N62909-14-1-N232). The raw composite materials and the autoclave manufacturing 398 process were generously provided by Hexcel Ltd. Finally, the doctoral study of B. Yu was 399 sponsored by the Croucher Foundation and the Cambridge Commonwealth, European \& 400 International Trust. 


\section{REFERENCES}

[1] K. Karthikeyan, B. P. Russell, N. A. Fleck, H. N. G. Wadley, and V. S. Deshpande, "The effect of shear strength on the ballistic response of laminated composite plates," Eur. $J$. Mech. A/Solids, vol. 42, pp. 35-53, 2013.

[2] J. P. Attwood, S. N. Khaderi, K. Karthikeyan, N. A. Fleck, M. R. Omasta, H. N. G. Wadley, and V. S. Deshpande, "The out-of-plane compressive response of Dyneema ${ }^{\circledR}$ composites," J. Mech. Phys. Solids, vol. 70, no. 1, pp. 200-226, 2014.

[3] K. Karthikeyan and B. P. Russell, "Polyethylene ballistic laminates: Failure mechanics and interface effect," Mater. Des., vol. 63, pp. 115-125, 2014.

[4] M. R. O’Masta, D. H. Crayton, V. S. Deshpande, and H. N. G. Wadley, "Mechanisms of penetration in polyethylene reinforced cross-ply laminates," Int. J. Impact Eng., vol. 86, pp. 249-264, 2015.

[5] J. P. Attwood, B. P. Russell, H. N. G. Wadley, and V. S. Deshpande, "Mechanisms of the penetration of ultra-high molecular weight polyethylene composite beams," Int. J. Impact Eng., vol. 93, pp. 153-165, 2016.

[6] W. J. Cantwell and J. Morton, "Comparison of the low and high velocity impact response of CFRP," Composites, vol. 20, no. 6, pp. 545-551, 1989.

[7] W. J. Cantwell and J. Morton, "Geometrical effects in the low velocity impact response of CFRP,” Compos. Struct., vol. 12, pp. 39-59, 1989.

[8] W. J. Cantwell and J. Morton, "Impact perforation of carbon fibre reinforced plastic," Compos. Sci. Technol., vol. 38, no. 2, pp. 119-141, 1990.

[9] O. Jørgensen and A. Horsewell, "On the indentation failure of carbon-epoxy cross-ply laminates, and its suppression by elasto-plastic interleaves," Acta Mater., vol. 45, no. 8, pp. 3431-3444, 1997.

[10] S.-W. R. Lee and C. T. Sun, "A Quasi-Static Penetration Model for Composite Laminates," J. Compos. Mater., vol. 27, no. 3, pp. 251-271, 1993.

[11] G. Zhou, "Damage mechanisms in composite laminates impacted by a flat-ended impactor," Compos. Sci. Technol., vol. 54, no. 3, pp. 267-273, 1995.

[12] F.-K. Chang, H. Y. Choi, and S.-T. Jeng, "Study on impact damage in laminated composites," Mech. Mater., vol. 10, no. 1-2, pp. 83-95, 1990.

[13] D. Liu, E. Lansing, and L. E. Malvern, "Cracking in Impacted Glass / Epoxy Plates," J. Compos. Mater., vol. 21, no. July 1987, pp. 594-609, 1987.

[14] H. Y. Choi, H.-Y. T. Wu, and F.-K. Chang, "A new approach toward understanding damage mechanisms and mechanics of laminated composites due to low-velocity impact: part II-analysis," J. Compos. Mater., vol. 25, no. 8, pp. 1012-1038, 1991.

[15] H. Y. Choi, R. J. Downs, and F.-K. Chang, "A new approach toward understanding damage mechanisms and mechanics of laminated composites due to low-velocity impact: part I-experiments," J. Compos. Mater., vol. 25, no. 1, pp. 992-1011, 1991. 
[16] N. Cristescu, L. E. Malvern, and R. L. Sierakowski, "Failure Mechanisms in Composite Rates Impacted by Blunt-Ended Penetrators," Foreign Object Impact Damage to Compos. A Symp., p. No. 568 p. 159, 1975.

[17] T.-W. Shyr and Y.-H. Pan, "Impact resistance and damage characteristics of composite laminates," Compos. Struct., vol. 62, no. 2, pp. 193-203, 2003.

[18] A. A. J. M. Peijs, R. W. Venderbosch, and P. J. Lemstra, "Hybrid composites based on polyethylene and carbon fibres Part 3: Impact resistant structural composites through damage management," Composites, vol. 21, no. 6, pp. 522-530, 1990.

[19] B. P. Russell, K. Karthikeyan, V. S. Deshpande, and N. A. Fleck, "The high strain rate response of Ultra High Molecular-weight Polyethylene: From fibre to laminate," Int. J. Impact Eng., vol. 60, pp. 1-9, 2013.

[20] C. A. Berg, J. Tirosh, and M. Israeli, "Analysis of short beam bending of fiber reinforced composites," Composite Materials: Testing and Design (Second Conference), ASTM STP 497, ASTM, pp. 206-218, 1972.

[21] C. C. Chamis and J. H. Sinclair, " $10^{\circ}$ Off-axis Test for Shear Properties in Fiber Composites," Exp. Mech., vol. 17, no. 9, pp. 339-346, 1977.

[22] D. E. Walrath and D. F. Adams, "The losipescu shear test as applied to composite materials," Exp. Mech., vol. 23, no. 1, pp. 105-110, 1983.

[23] C. S. de Ruijter, S. van der Zwaag, R. R. Stolze, and T. J. Dingemans, "Liquid crystalline matrix polymers for aramid ballistic composites," Polym. Compos., vol. 31, no. 4, pp. 612-619, 2010.

[24] Hexcel Composites, "HexPly 8552 epoxy matrix $\left(180^{\circ} \mathrm{C} / 356 \mathrm{~F}\right.$ curing matrix $)$, product data," 2013.

[25] B. Yu, S. N. Khaderi, V. S. Deshpande, and N. A. Fleck, "The effect of matrix shear strength on the out-of-plane compressive strength of CFRP cross-ply laminates. Combine," Unpubl. manuscript.

[26] H. M. Hsiao, I. M. Daniel, and R. D. Cordes, "Strain rate effects on the transverse compressive and shear behavior of unidirectional composites," J. Compos. Mater., vol. 33, no. 17, pp. 1620-1642, 1999.

[27] M. V. Hosur, J. Alexander, U. K. Vaidya, and S. Jeelani, "High strain rate compression response of carbon/epoxy laminate composites," Compos. Struct., vol. 52, no. 3-4, pp. 405-417, 2001.

[28] J.-L. Tsai and C. T. Sun, "Strain rate effect on in-plane shear strength of unidirectional polymeric composites," Compos. Sci. Technol., vol. 65, no. 13, pp. 1941-1947, 2005.

[29] R. M. Guedes, M. A. Vaz, F. J. Ferreira, and J. L. Morais, "Response of CFRP Laminates under High Strain Rate Compression until Failure," Sci. Eng. Compos. Mater., vol. 12, no. $1-2$, pp. 145-151, 2005.

[30] H. Koerber, J. Xavier, and P. P. Camanho, "High strain rate characterisation of unidirectional carbon-epoxy IM7-8552 in transverse compression and in-plane shear using digital image correlation," Mech. Mater., vol. 42, no. 11, pp. 1004-1019, 2010. 
[31] H. Cui, D. Thomson, A. Pellegrino, J. Wiegand, and N. Petrinic, "Effect of strain rate and fibre rotation on the in-plane shear response of $\pm 45^{\circ}$ laminates in tension and compression tests," Compos. Sci. Technol., vol. 135, pp. 106-115, 2016.

\section{Appendix A}

The matrix shear strength of the laminates was measured by performing short beam shear tests at quasi-static loading rates (following the recommendation in ASTM standard D2344). Rectangular short beams were cut from the above materials, of height $H=4 \mathrm{~mm}$, breadth $B=11 \mathrm{~mm}$, and length $L=25 \mathrm{~mm}$, and tested in three-point bending. The set-up consisted of one top roller with a diameter of $D=6 \mathrm{~mm}$ and two bottom rollers with diameters of $D=3 \mathrm{~mm}$, separated by a span length of $L_{S}=5 \mathrm{~mm}$. For consistency, specimens were placed such that fibres in the top ply were transverse to the rollers. The reaction force $F$ and the beam deflection $\delta$ were measured via a load cell and a laser extensometer, respectively. The short beam shear stress-strain responses were obtained by plotting the shear stress $\tau=3 F /(4 B H)$ versus shear strain $\bar{\gamma}=\delta / L_{S}$. Short beam shear tests were performed on materials (A) to (F). A minimum of five tests were conducted for each material at a shear strain rate of $\dot{\bar{\gamma}}=10^{-3} s^{-1}$. Results are listed in Table 1 .

In all tests, materials (A) and (B) showed a ductile shear response and the tests were 497 terminated at $\bar{\gamma}=40 \%$. For these materials, the matrix shear strength was defined as the shear stress at $\bar{\gamma}=5 \%$ and the shear modulus $G$ was the initial slope of the shear stress-strain response. In contrast, materials (C) to (F) exhibited an initial peak stress at $\bar{\gamma} \sim 5 \%$, and the peak stress was defined as the matrix shear strength. 


\section{FIGURE CAPTIONS}

503 Fig. 1. Sketch of the indirect tension mechanism in a pair of $0^{\circ}$ and $90^{\circ}$ plies under out-ofplane pressure. Poisson lateral expansion in the $0^{\circ}$ ply parallel to the fibre is less than in the $90^{\circ}$ ply transverse to the fibre. Under out-of-plane compression, this mismatch in Poisson lateral expansion induces tensile stress in the fibre direction of both plies and compressive stress in the transverse direction.

Fig. 2. The test set-up used in (a) quasi-static indentation; (b) quasi-static cropping; and (c) ballistic test. All dimensions are in $\mathrm{mm}$.

510 Fig. 3. Quasi-static indentation responses of the composite beams (A) to (F).

511 Fig. 4. Side views of the composite beams before and after failure initiation $($ at $t=0)$ in the 512 quasi-static indentation tests, for (a) material (A) and (b) material (F).

513 Fig. 5. Quasi-static cropping test for (a) materials (A) and (B); (b) materials (C) to (F).

514 Fig. 6. Optical images of interrupted cropping tests at $\bar{\gamma}=10 \%$ and $40 \%$ for (a) material (A);

515 (b) material (C); (c) material (F). The failure site of material (C) at $\bar{\gamma}=40 \%$ is labelled site $\mathrm{C}$ in part (b); for material (F) it is labelled site $F$ in part (c). High magnification views are given in part (d) for both sites $\mathrm{C}$ and $\mathrm{F}$.

518 Fig. 7. Cut fraction $f$ in materials (A) to (F) versus impact velocity $v_{0}$. Lines are drawn to 519 help reveal trends.

520 Fig. 8. Failure initiation velocity $v_{\text {init }}$ and penetration velocity $v_{p}$ plotted as functions of 521 matrix shear strength $\tau$. Lines are drawn to help reveal trends. in ballistic tests.

524 Fig. 10. High-speed image sequences recorded during the ballistic test of (a) material (A); (b) material (C); (c) material (F). Materials (A) and (C) failed by indirect tension, whereas material (F) failed by shear plugging. $t=0$ corresponds to the instant of impact. $t_{f}$ is defined to be the

527 time when fibre failure is first observed.

528 Fig. 11. Sketches of the failure mechanism of a composite beam when subjected to (a) 529 indentation and (b) cropping. 
530 Fig. 12. Plots of (a) predicted penetration velocity due to indirect tension failure $v_{I T}$ as a 531 function of $\bar{p}_{c}$ and (b) predicted penetration velocity due to shear plugging $v_{S P}$ as a function 532 of $\bar{\tau}_{c}$. Data for materials (A) to (F) are included.

533 Fig. 13. Plot of a dimensionless parameter $n=t_{f} c_{T} / H$ as a function of the matrix shear 534 strength $\tau$ in the composite beams. $c_{T}^{(i)}$ and $c_{T}^{(i i)}$ were calculated based on the through535 thickness tangent modulus of the composite beams measured from the quasi-static indentation 536 tests at $\bar{\varepsilon}=5 \%$ and $10 \%$, respectively. 
537 TABLE CAPTIONS

538 Table 1. Curing process and matrix shear strength of CFRP beams.

539 Table 2. Comparison between failure pressures as obtained from quasi-static indentation tests

540 and from out-of-plane compression tests.

541 Table 3. Comparison between peak shear strengths obtained from quasi-static cropping tests

542 and from short beam shear tests.

543 Table 4. Failure initiation velocity $v_{\text {init }}$ and penetration velocity $v_{p}$ of materials (A) to (F) in 544 the ballistic tests. 
Table 1. Curing process and matrix shear strength of CFRP beams.

\begin{tabular}{|c|c|c|c|c|c|c|}
\hline Material & $\begin{array}{l}\text { Curing } \\
\text { method }\end{array}$ & $\begin{array}{l}\text { Curing } \\
\text { temperature }\end{array}$ & $\begin{array}{c}\text { Curing } \\
\text { duration }\end{array}$ & $\begin{array}{l}\text { Applied } \\
\text { pressure }\end{array}$ & $\begin{array}{c}\text { Short } \\
\text { beam } \\
\text { shear } \\
\text { strength } \\
\tau(\mathrm{MPa})\end{array}$ & $\begin{array}{c}\text { Shear } \\
\text { Modulus } \\
G(\mathrm{GPa})\end{array}$ \\
\hline A & uncured & $\begin{array}{c}\text { room } \\
\text { temperature }\end{array}$ & -- & -- & $0.11^{1}$ & $0.005^{1}$ \\
\hline B & $\begin{array}{l}\text { oven } \\
\text { cured }\end{array}$ & $100^{\circ} \mathrm{C}$ & $2 \mathrm{hr}$ & $\begin{array}{c}\text { out-of- } \\
\text { plane } \\
0.1 \mathrm{MPa}\end{array}$ & $0.82^{1}$ & $0.06^{1}$ \\
\hline $\mathrm{C}$ & $\begin{array}{l}\text { oven } \\
\text { cured }\end{array}$ & $120^{\circ} \mathrm{C}$ & $2 \mathrm{hr}$ & $\begin{array}{c}\text { out-of- } \\
\text { plane } \\
0.1 \mathrm{MPa}\end{array}$ & $\begin{array}{c}22 \pm 1.9 \\
\mathrm{SD}\end{array}$ & $\begin{array}{c}0.9 \pm \\
0.08 \mathrm{SD}\end{array}$ \\
\hline $\mathrm{D}$ & $\begin{array}{l}\text { oven } \\
\text { cured }\end{array}$ & $120^{\circ} \mathrm{C}$ & $\begin{array}{c}2 \mathrm{hr} 15 \\
\min \end{array}$ & $\begin{array}{c}\text { out-of- } \\
\text { plane } \\
0.1 \mathrm{MPa}\end{array}$ & $\begin{array}{c}\text { 30. } \pm 1.3 \\
\text { SD }\end{array}$ & $\begin{array}{c}1.1 \pm \\
0.04 \mathrm{SD}\end{array}$ \\
\hline $\mathrm{E}$ & $\begin{array}{l}\text { oven } \\
\text { cured }\end{array}$ & $180^{\circ} \mathrm{C}$ & $24 \mathrm{hr}$ & $\begin{array}{c}\text { out-of- } \\
\text { plane } \\
0.1 \mathrm{MPa}\end{array}$ & $\begin{array}{c}61 \pm 3.7 \\
\mathrm{SD}\end{array}$ & $\begin{array}{c}1.3 \pm 0.1 \\
\mathrm{SD}\end{array}$ \\
\hline $\mathrm{F}$ & autoclaved & $180^{\circ} \mathrm{C}$ & $2 \mathrm{hr}$ & $\begin{array}{c}\text { out-of- } \\
\text { plane } \\
0.7 \mathrm{MPa}\end{array}$ & $\begin{array}{c}99 \pm 6.9 \\
\text { SD }\end{array}$ & $\begin{array}{c}1.8 \pm \\
0.07 \mathrm{SD}\end{array}$ \\
\hline
\end{tabular}

\footnotetext{
${ }^{1}$ Materials (A) and (B) are strain rate sensitive and their short beam shear test showed no shear failure. Therefore, the above short beam shear strengths $\tau$ represent the flow stresses at average shear strain of $5 \%$ and at an average shear strain rate of $\dot{\bar{\gamma}}=10^{-3} s^{-1}$.
} 
Table 2. Comparison between failure pressures as obtained from quasi-static indentation tests and from out-of-plane compression tests.

\begin{tabular}{|c|c|c|c|c|c|}
\hline Material & $\begin{array}{c}\text { Out-of- } \\
\text { plane } \\
\text { compression } \\
\text { average } \\
\text { failure } \\
\text { pressure } \\
\bar{p}_{f}{ }^{1}(\mathrm{MPa})\end{array}$ & $\begin{array}{c}\text { Indentation } \\
\text { average failure } \\
\text { pressure } \\
\bar{p}_{c}(\mathrm{MPa})\end{array}$ & $\begin{array}{c}\text { Indentation } \\
\text { apparent } \\
\text { modulus } \\
\text { at } \bar{\varepsilon}=5 \% \\
(\mathrm{GPa})\end{array}$ & $\begin{array}{c}\text { Indentation } \\
\text { apparent } \\
\text { modulus } \\
\text { at } \bar{\varepsilon}=10 \% \\
(\mathrm{GPa})\end{array}$ & $\begin{array}{c}\text { Ratio } \\
\text { between the } \\
\text { two tests } \\
\bar{p}_{c} / \bar{p}_{f}\end{array}$ \\
\hline $\mathrm{A}$ & 350 & 761 & 1.2 & 4.1 & 2.2 \\
\hline $\mathrm{B}$ & 865 & 781 & 2.4 & 4.5 & 0.9 \\
\hline $\mathrm{C}$ & 1240 & 812 & 4.5 & 5.6 & 0.7 \\
\hline $\mathrm{D}$ & 1230 & 922 & 5.2 & 6.3 & 0.8 \\
\hline $\mathrm{E}$ & 1220 & 1160 & 5.9 & 7.3 & 1.0 \\
\hline $\mathrm{F}$ & 1350 & 1250 & 6.4 & 7.9 & 0.9 \\
\hline
\end{tabular}

${ }^{1}$ Out-of-plane compression test results were obtained from tests with square-shaped specimen side length of $L \times L$ (with $L=10 \mathrm{~mm}$ ) at a strain rate of $\dot{\varepsilon}_{z z}=8 \times 10^{-4} \mathrm{~s}^{-1}$. 
Table 3. Comparison between peak shear strengths obtained from quasi-static cropping tests and from short beam shear tests, as taken from Table 1.

\begin{tabular}{|c|c|c|c|}
\hline Material & $\begin{array}{c}\text { Short beam shear } \\
\text { strength } \\
\tau(\mathrm{MPa})\end{array}$ & $\begin{array}{c}\text { Cropping test average } \\
\text { shear strength } \\
\bar{\tau}_{c}(\mathrm{MPa})\end{array}$ & $\bar{\tau}_{c} / \tau$ \\
\hline $\mathrm{A}$ & 0.11 & $0.05^{1}$ & 0.45 \\
\hline $\mathrm{B}$ & 0.82 & $0.4^{2}$ & 0.49 \\
\hline $\mathrm{C}$ & $22 \pm 1.9 \mathrm{SD}$ & 11 & 0.5 \\
\hline $\mathrm{D}$ & $30 . \pm 1.3 \mathrm{SD}$ & 32 & 1.1 \\
\hline $\mathrm{E}$ & $61 \pm 3.7 \mathrm{SD}$ & 38 & 0.62 \\
\hline $\mathrm{F}$ & $99 \pm 6.9 \mathrm{SD}$ & 67 & 0.67 \\
\hline
\end{tabular}

${ }^{1}$ Materials (A) and (B) showed no shear failure in the cropping test. Therefore, the above shear strengths are the average shear stress $\bar{\tau}_{c}$ at an average shear strain of 5\% and at an average shear strain rate of $10^{-3} s^{-1}$. 
553 Table 4. Failure initiation velocity $v_{\text {init }}$ and penetration velocity $v_{p}$ of materials (A) to (F) in 554 the ballistic tests.

\begin{tabular}{|c|c|c|c|}
\hline Material & $\begin{array}{c}\text { Failure initiation } \\
\text { velocity } v_{\text {init }}(\mathrm{m} / \mathrm{s})\end{array}$ & $\begin{array}{c}\text { Penetration velocity } \\
v_{p}(\mathrm{~m} / \mathrm{s})\end{array}$ & $v_{\text {init }} / v_{p}$ \\
\hline $\mathrm{A}$ & $141 \pm 17 \mathrm{SD}$ & $323 \pm 6 \mathrm{SD}$ & $0.44 \pm 0.12 \mathrm{SD}$ \\
\hline $\mathrm{B}$ & $<321$ & $338 \pm 12$ & -- \\
\hline $\mathrm{C}$ & $143 \pm 16 \mathrm{SD}$ & $309 \pm 8 \mathrm{SD}$ & $0.46 \pm 0.12 \mathrm{SD}$ \\
\hline $\mathrm{D}$ & $<125$ & $263 \pm 15 \mathrm{SD}$ & -- \\
\hline $\mathrm{E}$ & $<124$ & $181 \pm 6 \mathrm{SD}$ & - \\
\hline $\mathrm{F}$ & $64 \pm 8 \mathrm{SD}$ & $148 \pm 4 \mathrm{SD}$ & $0.43 \pm 0.13 \mathrm{SD}$ \\
\hline
\end{tabular}




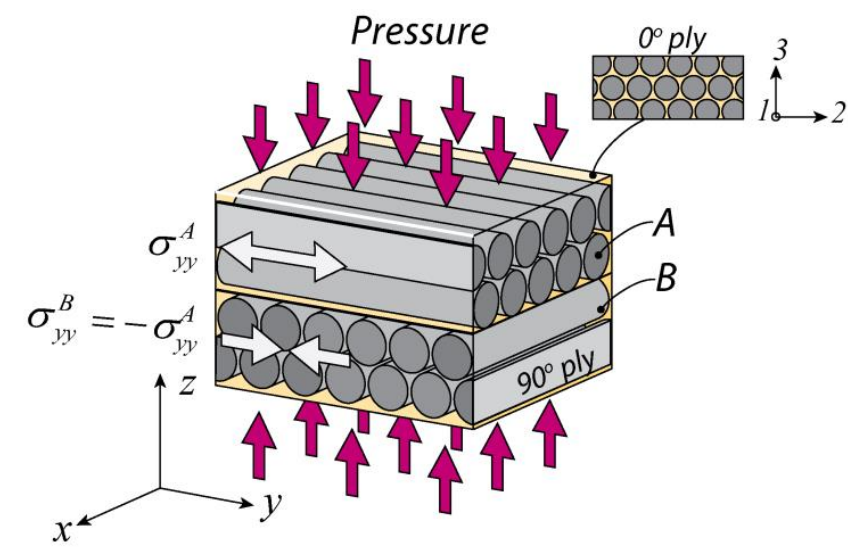

557 Fig. 1. Sketch of the indirect tension mechanism in a pair of $0^{\circ}$ and $90^{\circ}$ plies under out-of558 plane pressure. Poisson lateral expansion in the $0^{\circ}$ ply parallel to the fibre is less than in the $55990^{\circ}$ ply transverse to the fibre. Under out-of-plane compression, this mismatch in Poisson 560 lateral expansion induces tensile stress in the fibre direction of both plies and compressive 561 stress in the transverse direction. 
(a) Indentation Test

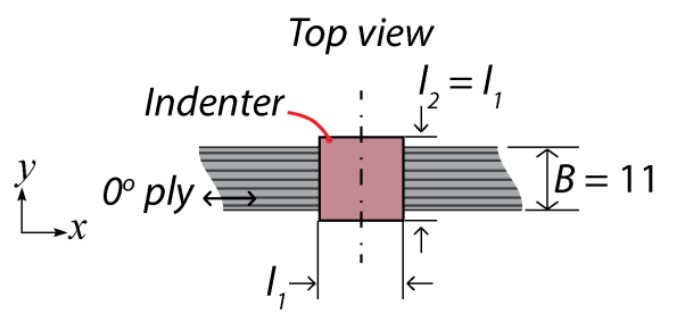

Profile view

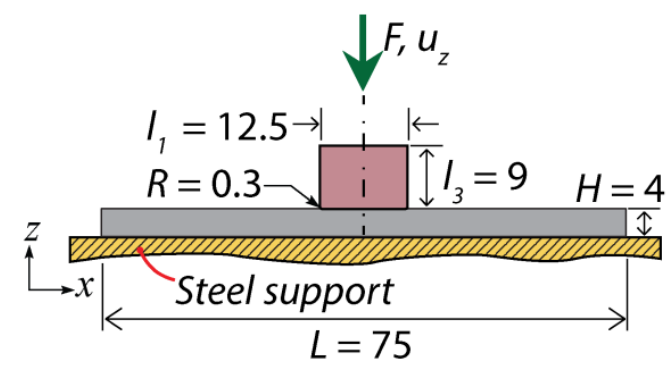

(c) Ballistic Test (b) Cropping Test

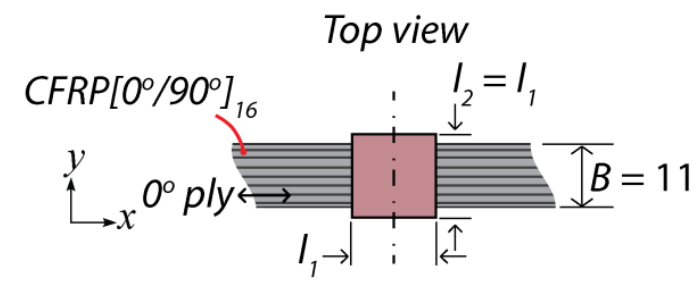

Profile view

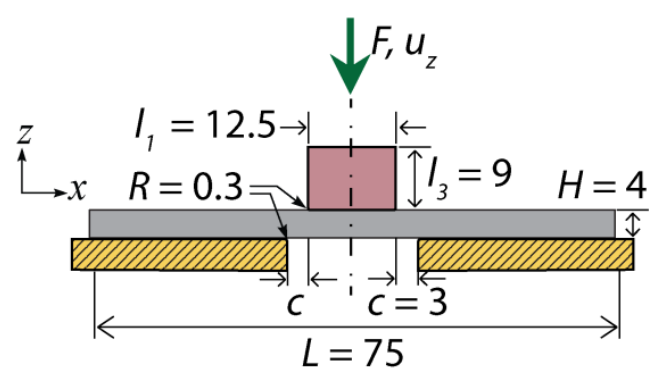

563 Fig. 2. The test set-up used in (a) quasi-static indentation; (b) quasi-static cropping; and (c) 564 ballistic test. All dimensions are in $\mathrm{mm}$. 


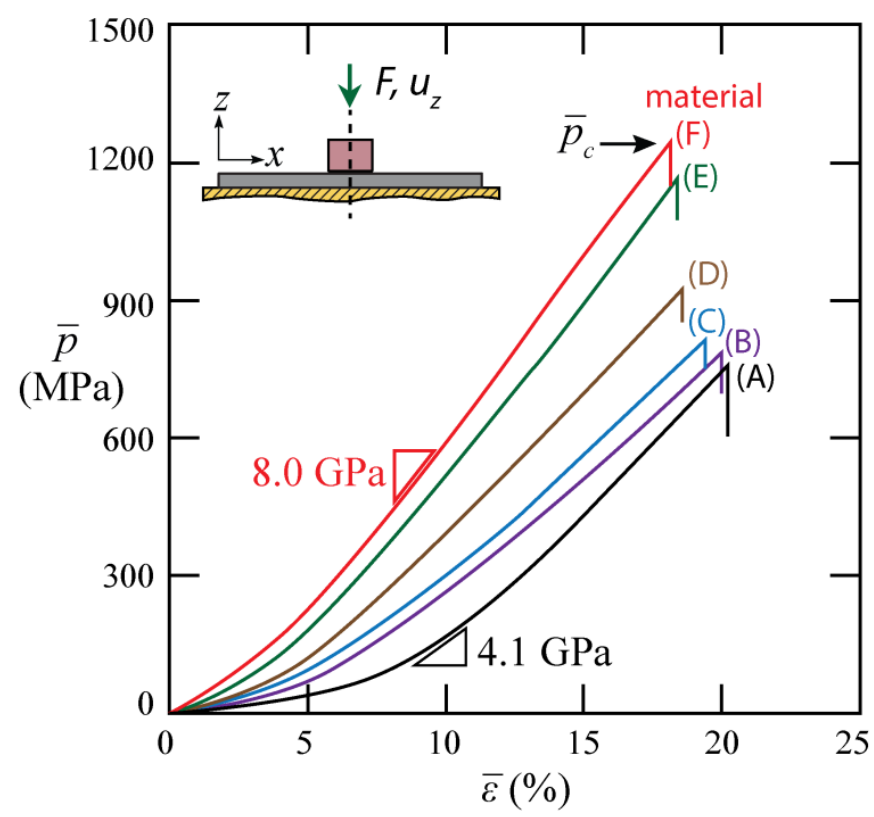

566

567 Fig. 3. Quasi-static indentation responses of the composite beams (A) to (F). 

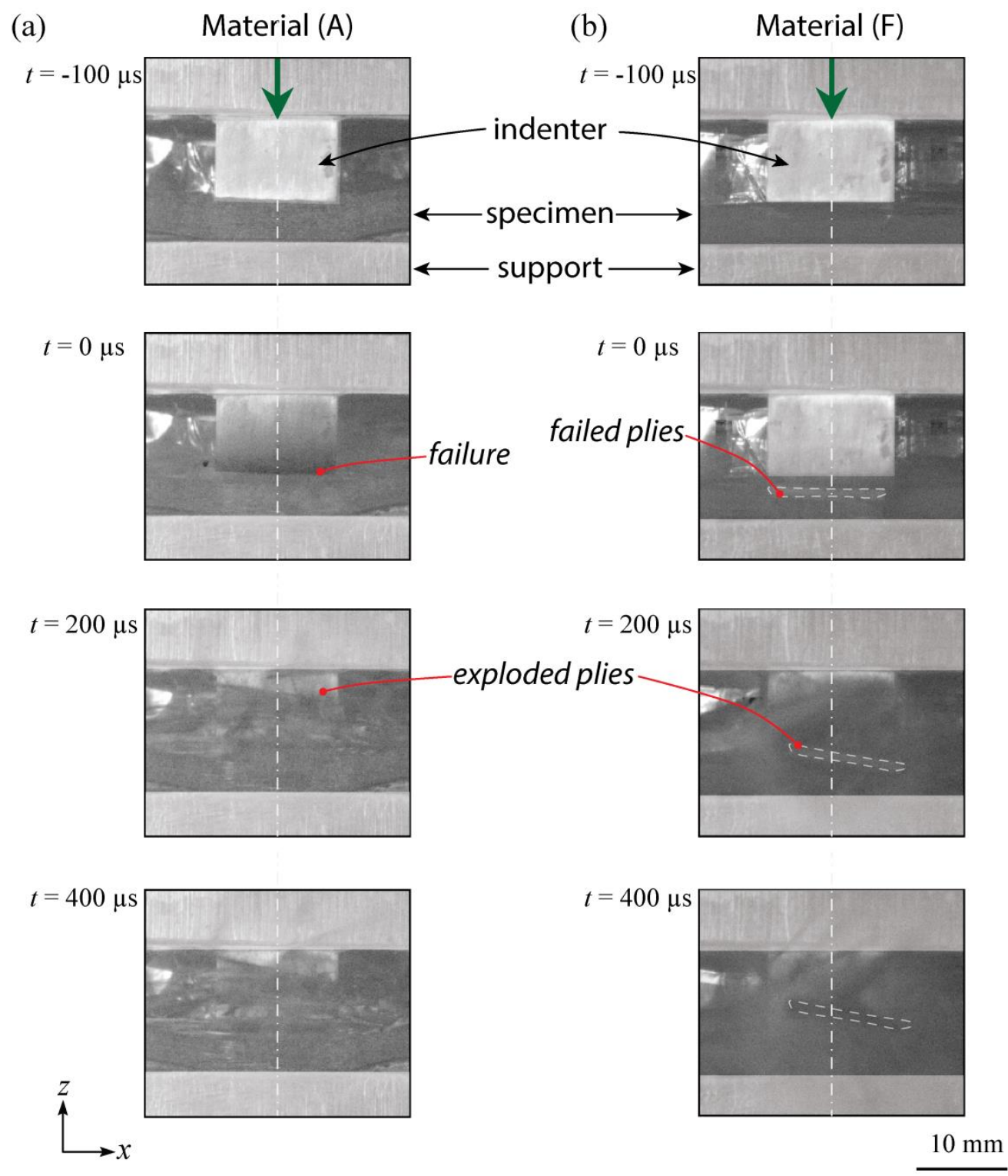

570 Fig. 4. Side views of the composite beams before and after failure initiation $($ at $t=0)$ in the 571 quasi-static indentation tests, for (a) material (A) and (b) material (F). 
(a)

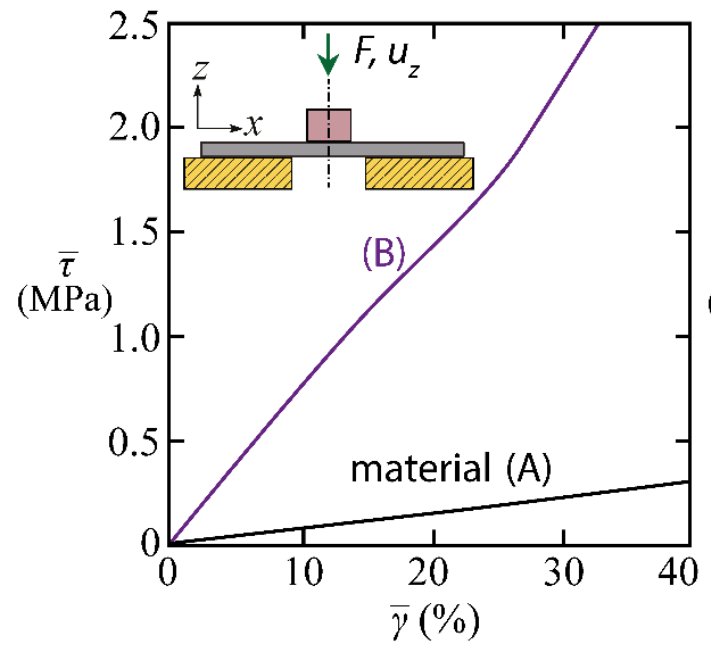

(b)

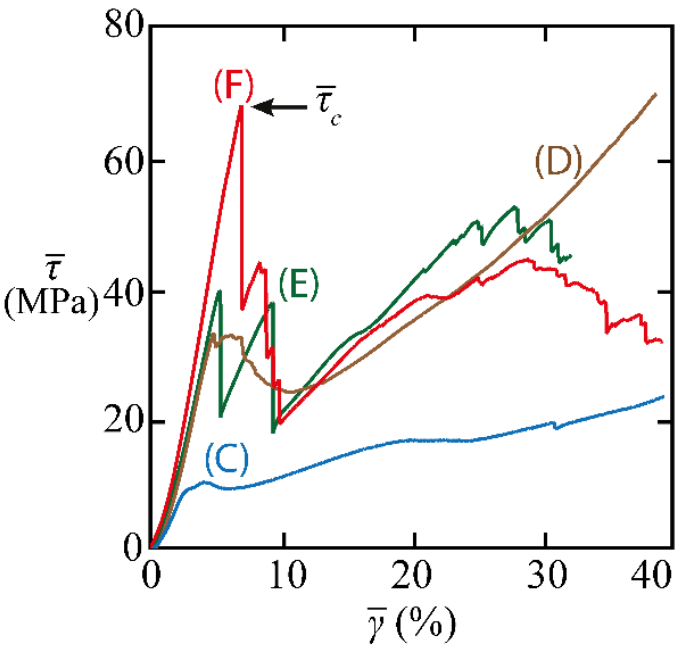

574 Fig. 5. Quasi-static cropping test for (a) materials (A) and (B); (b) materials (C) to (F). 
(a) Material

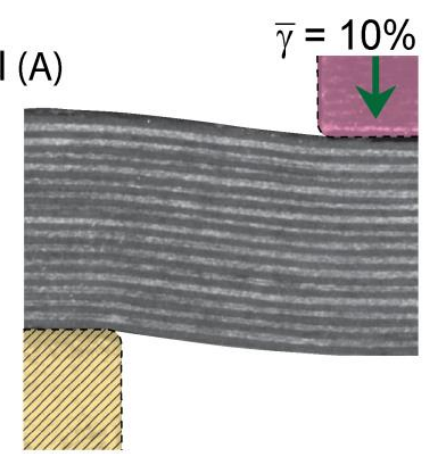

(b) Material (C)

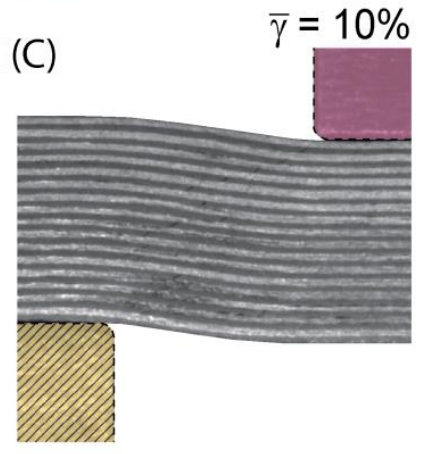

(c) Material (F)

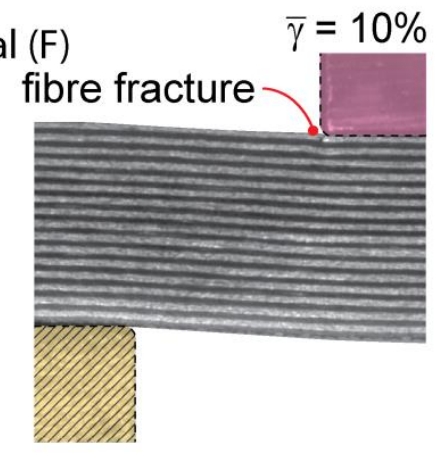

(d)

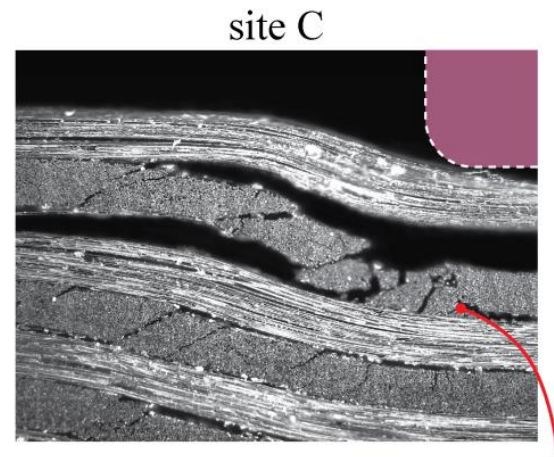

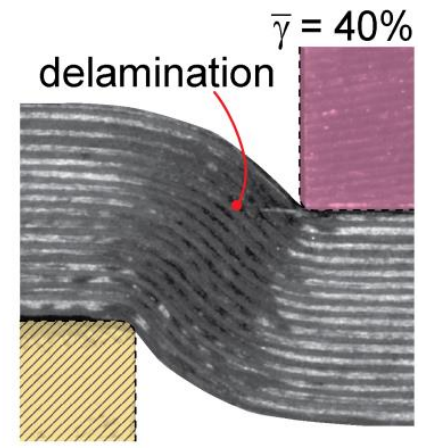
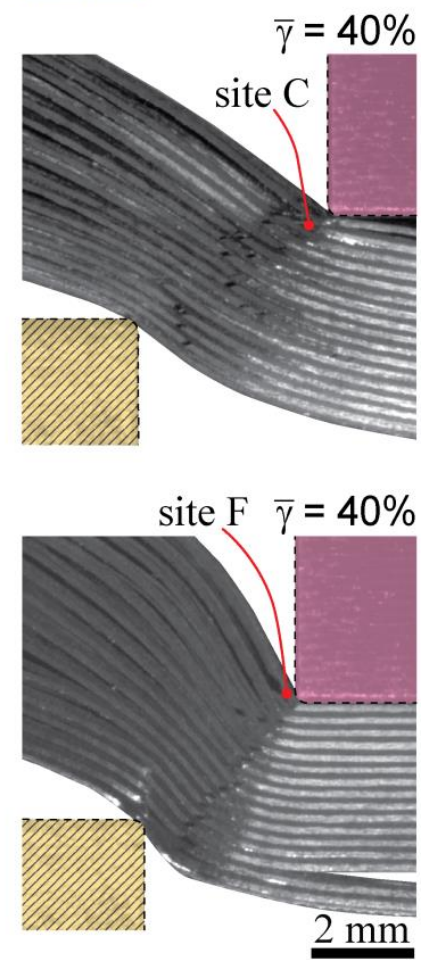

site $\mathrm{F}$

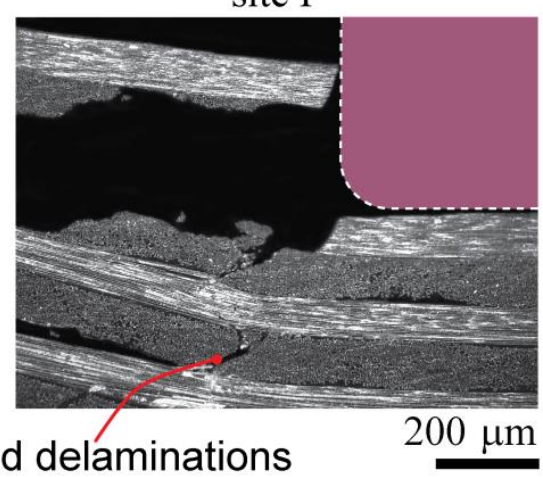

577 Fig. 6. Optical images of interrupted cropping tests at $\bar{\gamma}=10 \%$ and $40 \%$ for (a) material (A);

578 (b) material (C); (c) material (F). The failure site of material (C) at $\bar{\gamma}=40 \%$ is labelled site $\mathrm{C}$

579 in part (b); for material (F) it is labelled site F in part (c). High magnification views are given

580 in part (d) for both sites $\mathrm{C}$ and $\mathrm{F}$. 


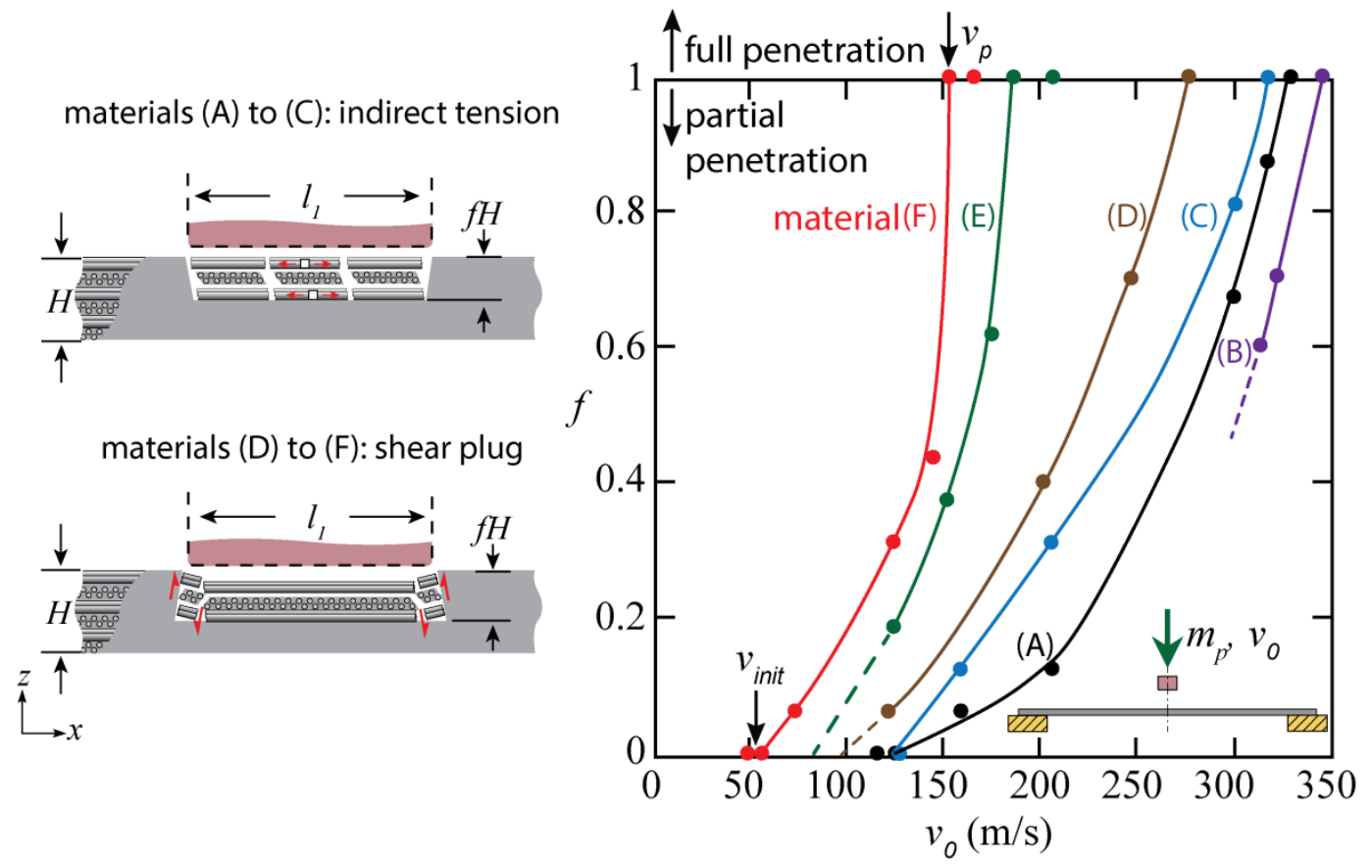

582

583 Fig. 7. Cut fraction $f$ in materials (A) to $(\mathrm{F})$ versus impact velocity $v_{0}$. Lines are drawn to 584 help reveal trends. 


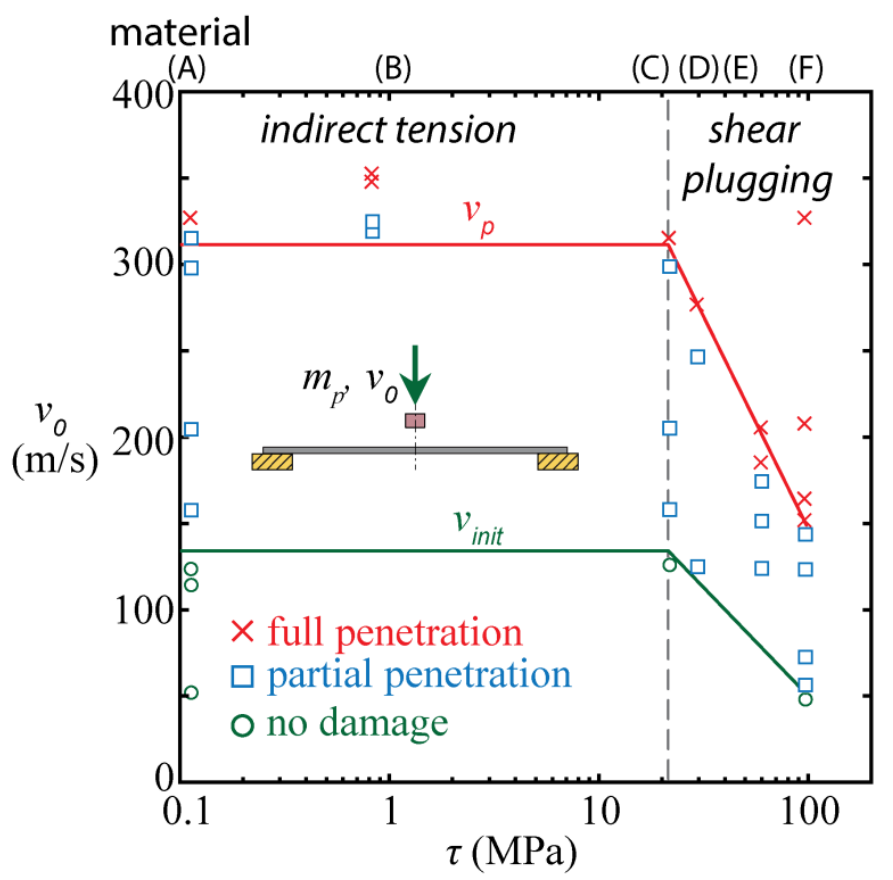

587 Fig. 8. Failure initiation velocity $v_{\text {init }}$ and penetration velocity $v_{p}$ plotted as functions of 588 matrix shear strength $\tau$. Lines are drawn to help reveal trends. 


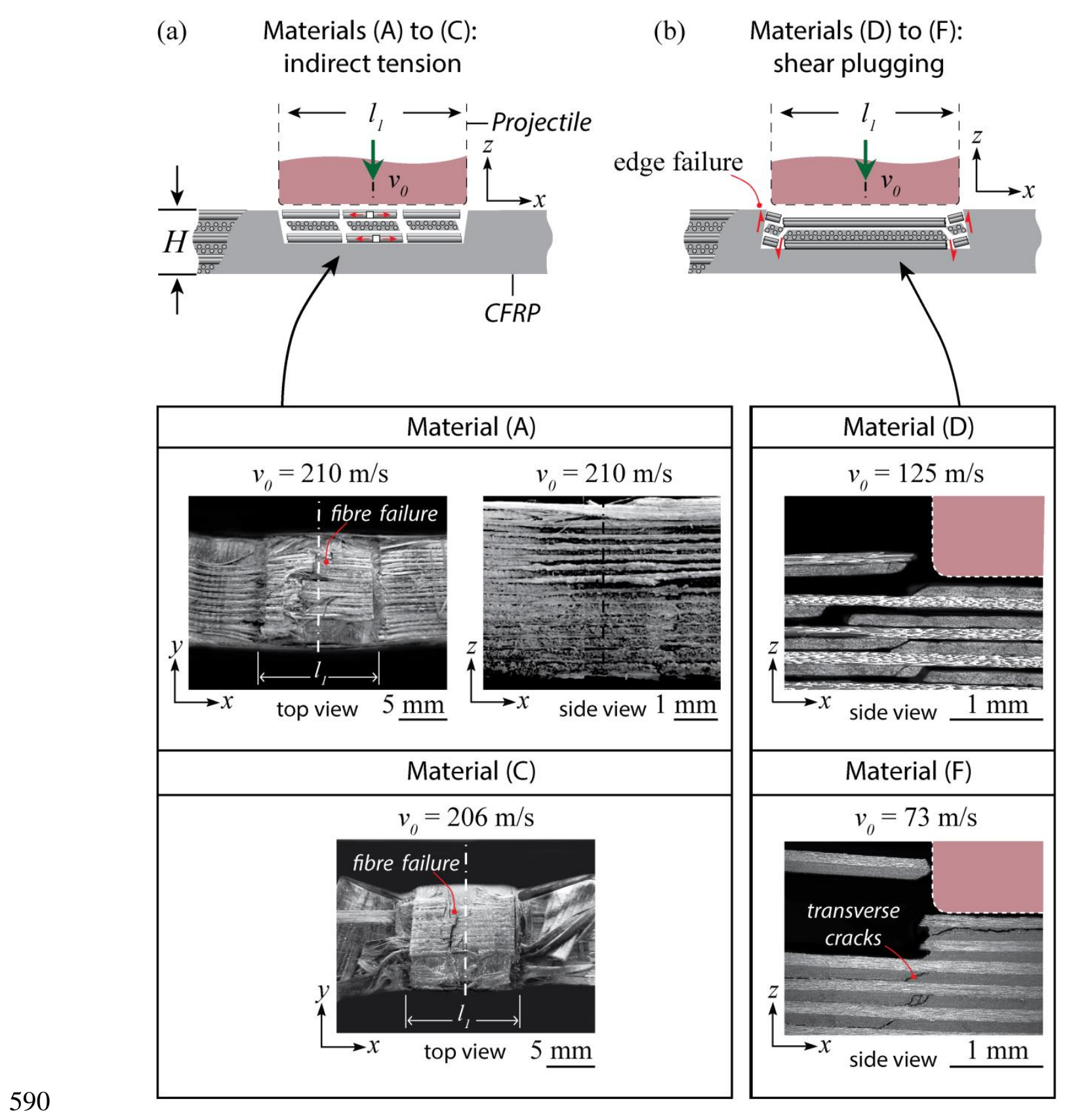

591 Fig. 9. Sketches and optical images of (a) indirect tension and (b) shear plugging mechanisms 592 in ballistic tests. 


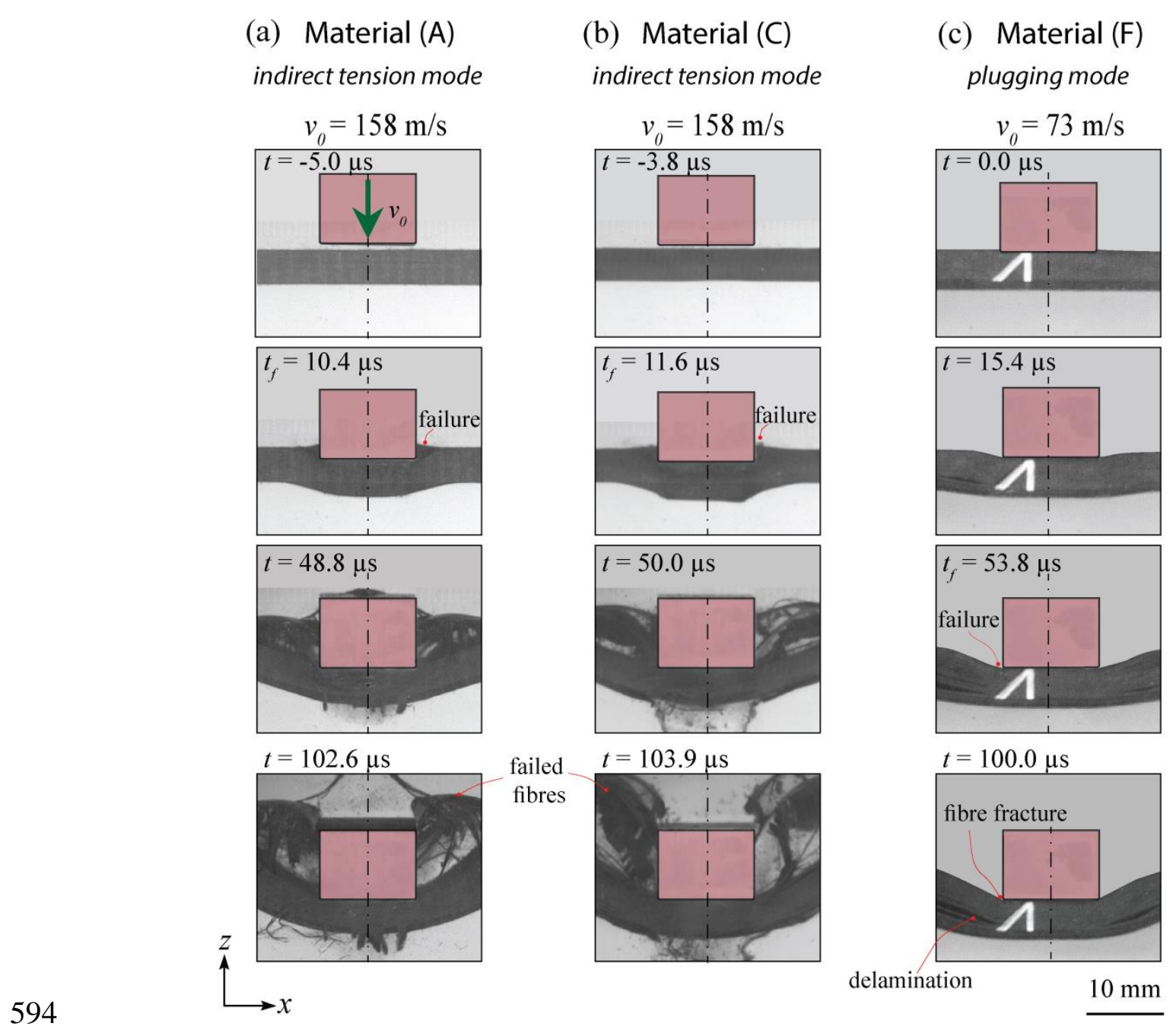

595 Fig. 10. High-speed image sequences recorded during the ballistic test of (a) material (A); (b) 596 material (C); (c) material (F). Materials (A) and (C) failed by indirect tension, whereas material 597 (F) failed by shear plugging. $t=0$ corresponds to the instant of impact. $t_{f}$ is defined to be the 598 time when fibre failure is first observed. 
(a) Indentation Test

600

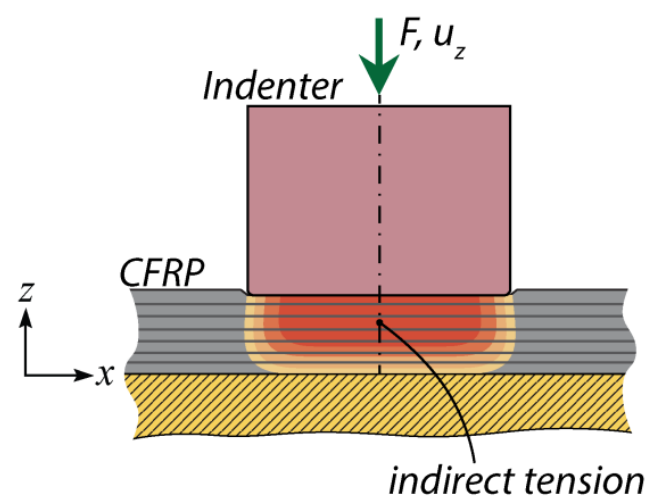

(b) Cropping Test

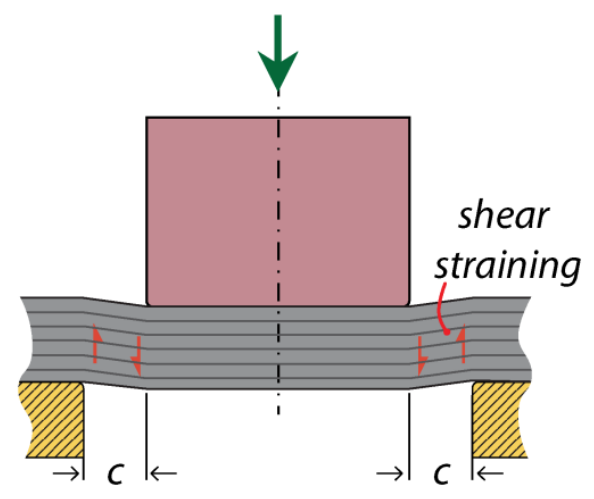

601 Fig. 11. Sketches of the failure mechanism of a composite beam when subjected to (a) 602 indentation and (b) cropping.

603 
(a)

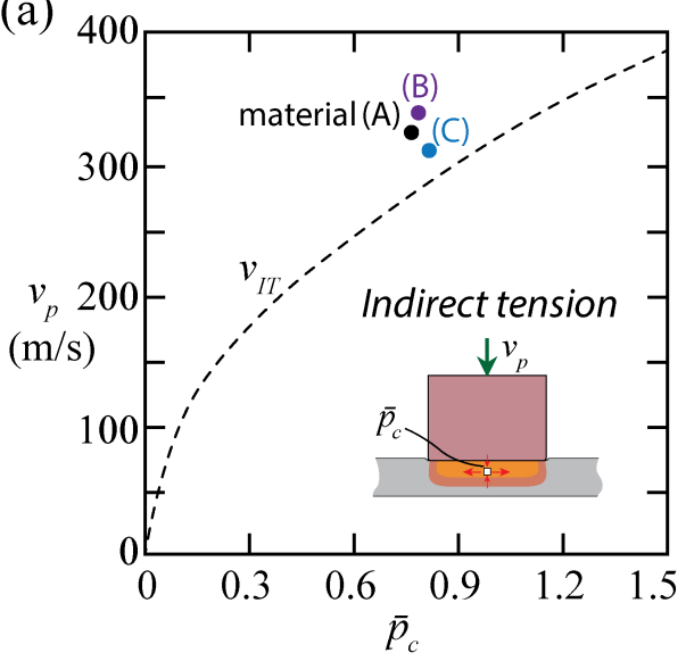

$(\mathrm{GPa})$ (b)

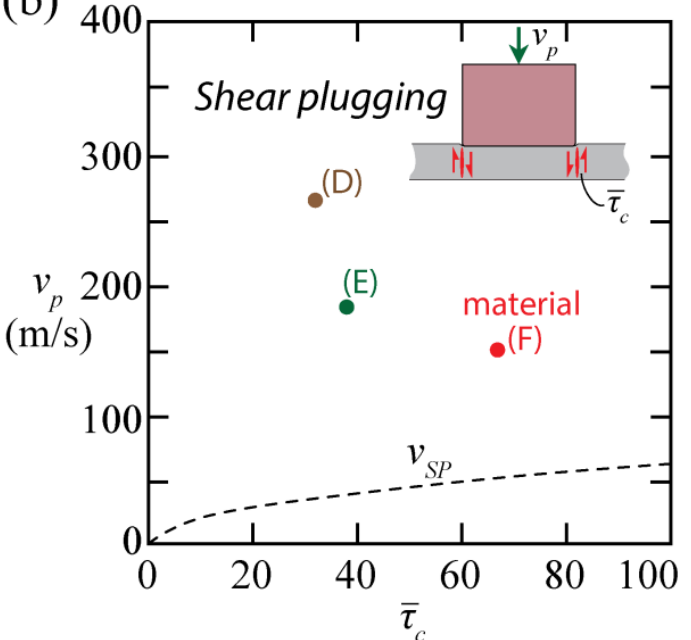

(MPa)

605 Fig. 12. Plots of (a) predicted penetration velocity due to indirect tension failure $v_{I T}$ as a 606 function of $\bar{p}_{c}$ and (b) predicted penetration velocity due to shear plugging $v_{S P}$ as a function 607 of $\bar{\tau}_{c}$. Data for materials $(\mathrm{A})$ to $(\mathrm{F})$ are included.

608 


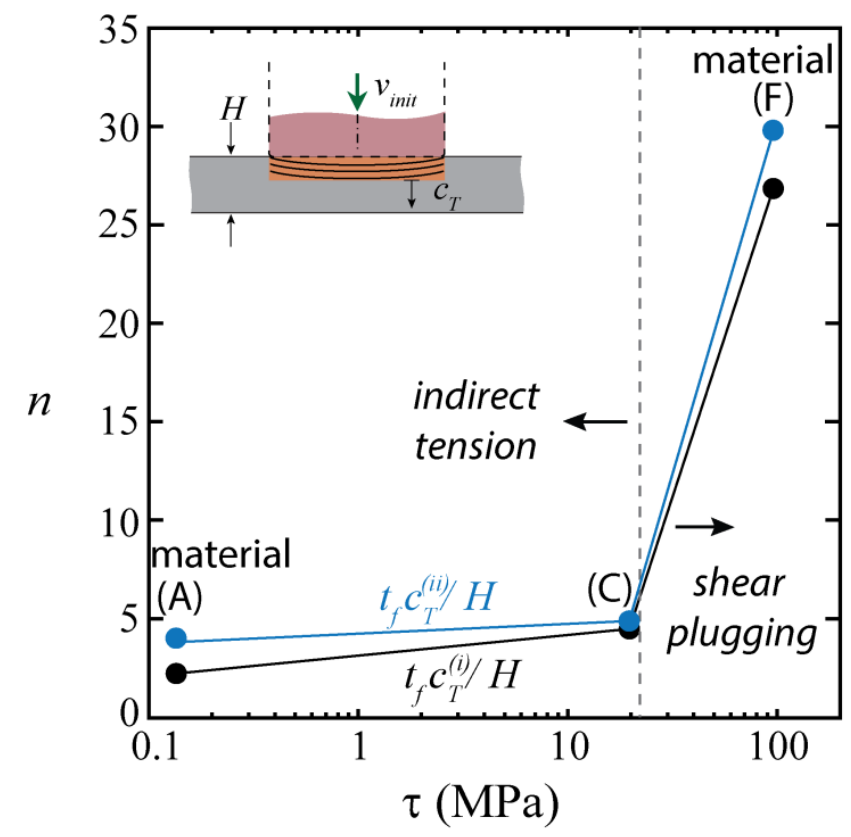

610 Fig. 13. Plot of a dimensionless parameter $n=t_{f} c_{T} / H$ as a function of the matrix shear 611 strength $\tau$ in the composite beams. $c_{T}^{(i)}$ and $c_{T}^{(i i)}$ were calculated based on the through612 thickness tangent modulus of the composite beams measured from the quasi-static indentation 613 tests at $\bar{\varepsilon}=5 \%$ and $10 \%$, respectively. 